\title{
De'sign and Simulation of Water Level Monitoring and Control System in Mini Hydro Power Plant
}

\author{
Mulyono \\ Department of Mechanical Engineering \\ Swiss German University \\ Tangerang 15143, Indonesia \\ Email: moeloviana@yahoo.co.id
}

\author{
Hanny J. Berchmans \\ Department of Mechanical Engineering \\ Swiss German University \\ Tangerang 15143, Indonesia
}

\begin{abstract}
In common mini hydro power plants in Indonesia, the control of water levels in intake, sand-trap and head pond is carried out manually. This conventional manual control system may cause damages of waterway and all its components due to overflow or transient flow of water during load shedding or black out of electricity grid. The damages eventually may increase cost of maintenance and increase the risk of waterway collapse or excessive water hammer in penstock pipe. This type of collapses often happen in many mini hydro power plants in Indonesia. The risk of damages can be reduced by installing water level control and monitoring system in all key water way components such as in intake, sand-trap and head pond. Some other mini hydro power plants have installed water level control and monitoring system. But the price of such control system is still very expensive and high operation and maintenance cost. Thus, this thesis work designs and simulates simple and inexpensive the water level control and monitoring system for a mini hydro power plant. In this thesis work, the design and simulation of the water level control and monitoring system are carried out by a simulated three water tanks where the water levels in the tanks are monitored and controlled by using ultrasonic level sensors and motorized valves respectively. A simple and inexpensive Arduino based water level control and monitoring system is successfully designed to fulfil the requirement of quick or fast respond for water level control in the simulated model.
\end{abstract}

Keywords: Water Level, Mini Hydro Power Plant, Control and Monitoring, Ultra Sonic Sensor, Arduino.

\section{INTRODUCTION}

Hydroelectric power plant is a renewable energy generation power plant that utilised potential energy of water. Smallscale hydropower plant first used of electricity generation in Indonesia the early of the 20th century. Many mini hydro power plants have been developed in most parts of the world, including Indonesia, to generate electricity for the need of electrification in rural area.

Basically the work of a mini hydro power plant is explained in this way: (i) water from the river is flowed through an intake, where the water level in intake is controlled by a dam and two (2) water gates, (ii) water from intake then is flowed through a section channel to a sand trap, (iii) in the sand trap, the sand or soil that is deposited is taken, (iv) water then flows in long section of waterways into a head pound head.

The water in the head pond then is flowed through penstock. Kinetic energy of water in the penstock is used to drive the hydraulic turbine. In the hydraulic turbine, kinetic energy of water in converted into mechanical energy of hydraulic turbine. Then by a generator, the mechanical energy of hydraulic turbine is converted into electrical energy. The produced electricity is transported to electricity grid to fulfil the electricity demand. A mini hydro power in a run of river type of hydro power plat where it does not need large dams for water storage. The mini hydro power plant system is a low-cost way to generate electricity for rural people area in the remote area. This type of power plant can also prevent environmental damage such as flooding. A simple schematic diagram of mini hydro power plant shown in Figure 1.

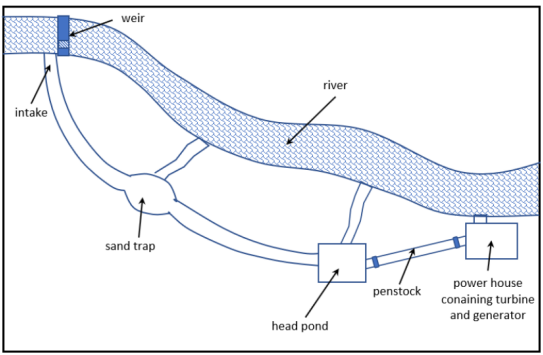

Fig. 1. The Mini Hydro Power Plant

\section{OBJeCtives}

The objectives of the research are:

- Design and simulate a model of water level monitoring and control system for mini hydro power to monitor and regulate the opening of the valve so that the operation of the can be done safely and effectively at any load or transient condition in the upstream and downstream of the power plant.

- Design a control that can prevent water in the channel and head pond tank from overflowing when the penstock pipe closes suddenly. 


\section{Theoritical Perspective}

Mini hydro power plants are conventional energy sources. Consisting of two main parts, mechanical parts include turbines, anchors, controllers, hydraulic servo motors, control valves, etc. The electric part consists of a generator and load. The combined form of hydraulic turbines, controls, and hydroelectric systems is known as the water turbine Governor.

The stored water at head contains potential energy. This energy is changed to kinetic energy. When it is allowed to pass through the penstock, this kinetic energy is converted to mechanical energy which allows water to fall on the runner blades of the turbine. The shaft of the turbine was coupled to the generator, the generator produces electrical energy by changing the mechanical energy into electrical energy. The speed governing of turbine is used to adjusts the generator speed based on the feedback signals of the deviations of both system frequency and power with respect to their reference settings. This system results that power generation at synchronous frequency.

\section{DESIGN OF EXPERIMENTAL}

The design of the system can be seen in Figure 2 and the scheme of the mini hydro power plant control and the configuration of the component on Arduino PIN can be seen in Figure 3.

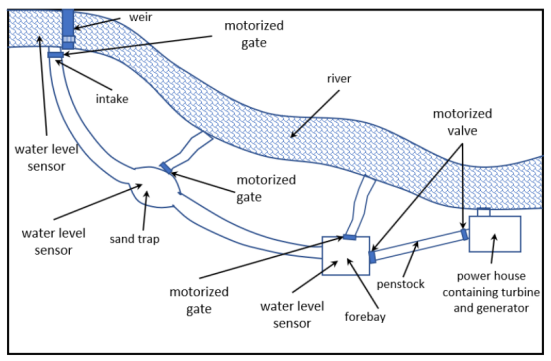

Fig. 2. Design of Experiment

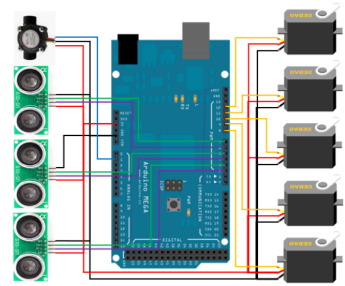

Fig. 3. Schematic Diagram of the Components.

The scheme control (Fig.4) and the algorithm of the system (Fig.5).

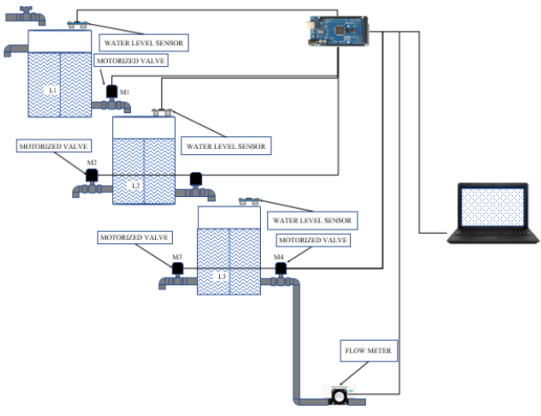

Fig. 4. Scheme of the Control
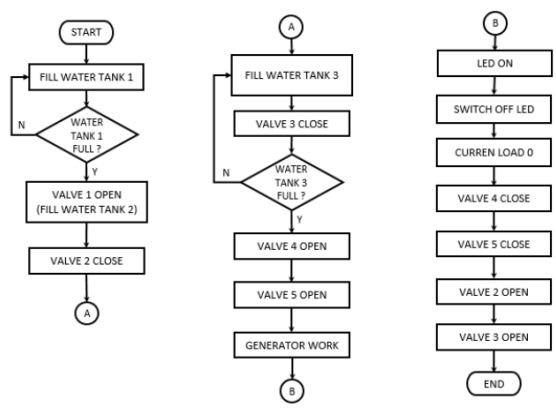

Fig. 5. Algorithm of the System.

\section{EXPERIMENT RESULT}

\section{A. The Process of Filling Water}

Tank 1, 2 and 3 are initially emptied, then filled with some water. The water level in the tank at any given time is recorded. After the data is obtained, a curve is made between the time to the water level in the tank. This step is then carried out also for tank 2 and 3 . The flow chart of the filling water tank can be seen in Figure 6.

Testing in initial condition is water level is empty. The result shown in Figure 7.

The second step is fill water to the tank 1 , so servo 1 is open then water flow to the tank 2 , then water flow out to the tank 3 so servo 2 and 3 is open.

\section{B. The process of empty water}

When all three tanks are full, valve 1, 3 and 5 are closed, while valve 2 and 4 are opened. The flow chart of the empty water tank can be seen in Figure 8.

When the valve is closed, flow rate sensor becomes zero so all servo is closed and the drain is opened, The monitor was shown as seen in Figure 9. 


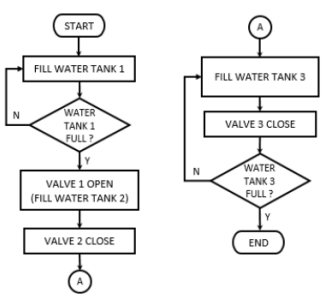

Fig. 6. The Process of Filling Water.

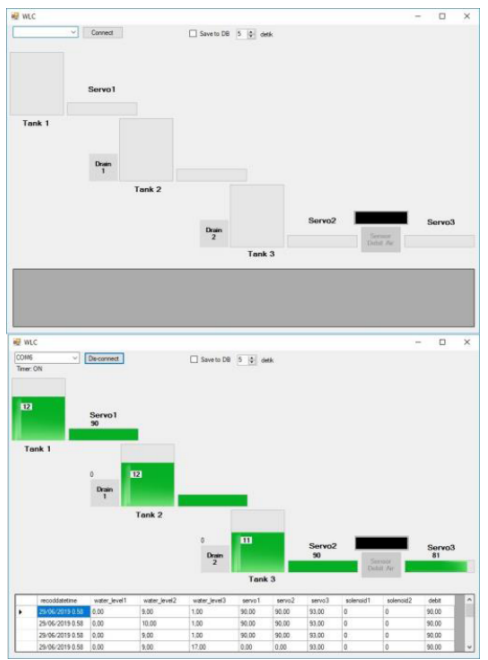

Fig. 7. First Respons.

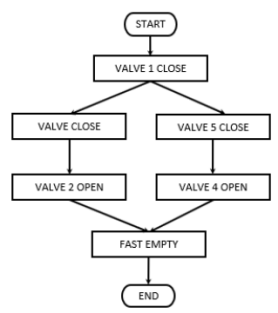

Fig. 8. The Flow Chart of the Fast Empty Water.

The other way to empty the water is when all three tanks are full, valve 1,3 and 5 are closed, while valve 2 and 4 are

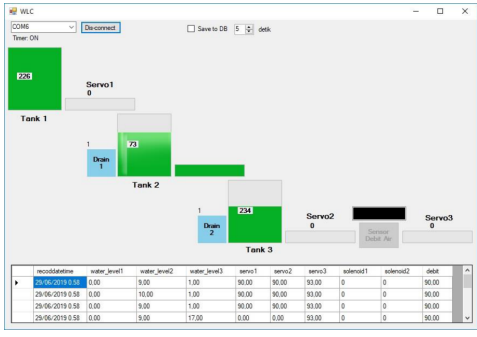

Fig. 9. Third Response.

opened. This time need more time than empty step above. The flow chart of the empty water tank can be seen in Figure 10.

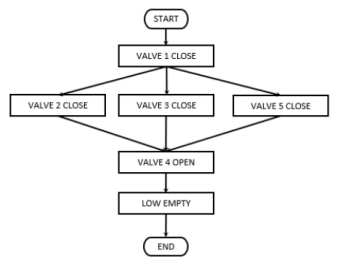

Fig. 10. The flow chart of the fast empty water.

The test of the system is done by experiment, assuming that the cross-sectional channel on the mini hydro power plant is 29 $\mathrm{cm} \times 39 \mathrm{~cm}$, here we will calculate the time to empty the tank. In the first test, when there was no load (load current equaled zero) then motorized valve M4 and M5 closed, motorized M3 opened and M2 remained closed. With this condition, the water will come out through the M3. Here we will calculate the time taken so that the water in tanks 2 and 3 runs out.

$$
\begin{aligned}
\sum_{V o l} & =V_{2}+V_{3} \\
& =A \times L_{1}+A \times L_{2} \\
& =0.17 \times 0.17 \times(20-3)+0.17 \times 0.17 \times(20-3) \\
& =0.03845 \mathrm{~cm}^{3}
\end{aligned}
$$

The time needed to empty tanks 2 and 3 is:

$$
\begin{aligned}
t_{\text {water }} & =\frac{\text { total }}{\text { discharge }_{\text {volume }}} \\
& =\frac{0.03845}{0.001326} \\
& =124 \text { seconds }
\end{aligned}
$$

In the second test, when there was no load (load current equaled zero) the motorized valve M4 and M5 closed, motorized M2 and M3 opened simultaneously. Here we will 

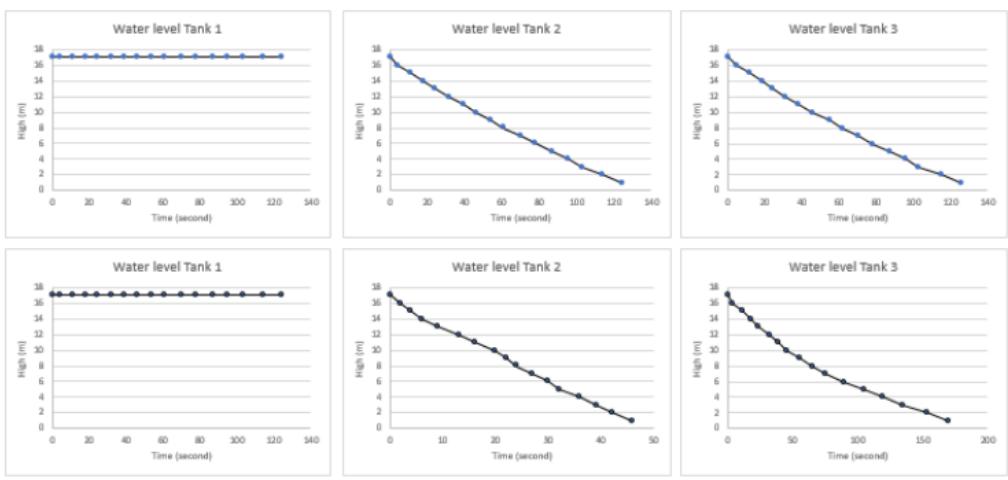

Fig. 11. Water Level Monitoring.

calculate the time needed so that the water at level 2 and 3 runs out.

The time needed to empty Tank 2 is:

$$
\begin{aligned}
t_{\text {water }} & =\frac{\text { Volume }_{V 2}}{\text { water }_{\text {discharge }} \times 2} \\
& =\frac{0.019227}{0.001326 \times 2} \\
& =46 \text { seconds }
\end{aligned}
$$

The total volume in Tank 3 is:

$$
\begin{aligned}
\text { Total }_{\text {volume }} & =\frac{\text { Volume }_{V 2}}{2}+\text { Volume }_{V 3} \\
& =\frac{0.019227}{2}+0.019227 \\
& =0.0288405 \mathrm{~m}^{3}
\end{aligned}
$$

The time needed to empty Tank 3 is

$$
\begin{aligned}
t_{\text {water }} & =\frac{\text { total }}{\text { discharge }_{\text {volume }}} \\
& =\frac{0.0288405}{0.001326} \\
& =170 \text { seconds }
\end{aligned}
$$

\section{CONCLUSION}

Designs and simulates simple water level control and monitoring system for a mini hydro power plant was carried out by a simulated three water tanks where the water levels in the tanks are monitored and controlled by using ultrasonic level sensors and motorized valves respectively. A simple and inexpensive Arduino based water level control and monitoring system is successfully designed to fulfil the requirement of quick or fast respond for water level control in the simulated model. Design can be implemented in the real mini hydropower plant, but the condition have same condition with the simulation. Design may not work due to enviromental factors such as weather and rain.

\section{RECOMMENDATIONS}

Design a simulated water level control and monitoring system with high specification equipment. Design a cordless monitoring water level because that place is far each other.

\section{REFERENCES}

[1] Prawin Angel Michael, C. P. Jawahar, Design of $15 \mathrm{~kW}$ Mini Hydro Power Plant for Rural Electrification at Valara, 1st International Conference on Power Engineering, Computing and Control, PECCON-2017, 2- 4 March 2017, VIT University, Chennai Campus

[2] Okonkwo G. N and Ezeonu S. O., Design and installation of a mini hydro electric power plant, 2012 Scholarly Journal of Engineering Research Vol. 1(1), pp. 11-15. March 2012

[3] Anil Kunwor, Technical Specifications of Mini Hydropower System Design and Its Implementation, Feasibility Analysis and Design of Lamaya Khola Mini Hydro Power Plant, 2012 Bachelors Degree Thesis Industrial Management, Arcada.

[4] Rabiu Aliyu Abdulkadir, Modelling and Simulation of Mini Hydro Power Plant Using MatLAB Simulink, September 2015 Department of Electrical and Electronic Engineering, Near East University

[5] Lie Jasa, Mauridhi Hery Purnomo, and Ardyono Priyadi, PID Control for Mini-Hydro Power Plants based on Neural Network, 2012, Proceedings of the IASTED Conference April 2 - 4, 2012 Phuket, Thailand

[6] Mahmut Temel Ozdemira, An experimental system for electrical and mechanical education: Mini hydro power plant prototype, 2012 Procedia - Social and Behavioral Sciences 47 ( 2012 ) 21142119 Firat University, Department of Electrical and Electronics Engineering, Elazig23119, Turkey

[7] K. Anil Naika, P. Srikanthb, and Pankaj Negic, IMC Tuned PID Governor Controller for Hydro Power Plant with Water Hammer Effect, 2012 Procedia Technology 4 ( 2012 ) 845853 Assistant Professor,IMS Engineering College,Ghaziabad,201009,India

[8] Keki R. Bhote and and Adi K. Bhote (2000), World class quality: Using Design of Experiments to Make It Happen. AMACOM, a division of American Management Association, New York. ISBN: 0-8144-0427-8.

[9] Matt Davisona, Guangzhi Zhao, Optimal Control of Two-Dam Hydro Facility, 2012 Systems Engineering Procedia 3 (2012) 112 The University of Western Ontario, London, ON, N6A 5B7, Canada

[10] Beza Negash Getu, Water Level Controlling System Using Pid Controller, 2016 International Journal of Applied Engineering Research ISSN 0973-4562 Volume 11, Number 23 (2016).

[11] Ashish Kumar Singh, Control of Multi Tank System and Their Performance analysis, 2014 Department of Electronics \& Communication Engineeringn National Institute of Technology Rourkela 